\title{
Effect of a clown's presence at botulinum toxin injections in children: a randomized, prospective study
}

This article was published in the following Dove Press journal: Journal of Pain Research

20 September 2011

Number of times this article has been viewed

\author{
Lars Kjaersgaard Hansen' \\ Maria Kibaek' \\ Torben Martinussen ${ }^{2}$ \\ Lene Kragh ${ }^{3}$ \\ Mogens Hejl' \\ 'Department of Paediatrics, \\ Hans Christian Andersen Children's \\ Hospital, Odense University Hospital, \\ Odense; ${ }^{2}$ Roskilde Hospital, Roskilde; \\ ${ }^{3}$ Department of Statistics, University \\ of Southern Denmark, Odense, \\ Denmark
}

Background: The effect of the presence of a hospital clown during pediatric procedures has rarely been evaluated. In a pediatric ward, botulinum toxin injection is a painful procedure and a stressful experience for the child. We undertook a study of the effect of the presence of a hospital clown on children treated with botulinum toxin in an outpatient setting.

Methods: In total, 60 children, the majority of whom had spastic cerebral palsy, were subjected to a total of 121 botulinum toxin treatment sessions. Thirty-two children were being treated for the first time. During a 2-year period, we enrolled 121 treatment sessions prospectively, and the children were randomized to either the presence of a female clown during treatment or to no presence of a clown. The duration of the child's crying during the procedure was used as an indicator of the effect of the presence of a clown.

Results: The effect of the clown was significantly related to patient gender. Girls were found to have a significantly shorter period of crying when the clown was present. For children younger than 8 years, the effect on boys was negative. Children treated for the first time did not appear to benefit from the presence of the clown, and showed no difference in effect between genders.

Conclusion: No effect of the clown was documented for children being treated for the first time. At repeat treatments, we saw a positive effect of the female clown in relation to girls, and a negative effect on boys younger than 8 years of age.

Keywords: clown, injections, pain, botulinum toxin

\section{Introduction}

A Cochrane review has concluded that the presence of parents during induction of general anesthesia does not reduce children's anxiety. ${ }^{1}$ Distraction by a hand-held video game was shown to reduce anxiety both in the preoperative area and during induction of anesthesia, as well as being more efficacious than parental presence or midazolam. ${ }^{1-3}$ A Cochrane review of psychological interventions for needle-related pain and distress in children suggests distraction and cognitive behavioral interventions and hypnosis are successful. ${ }^{4}$ Breathing exercises and nurse-led distraction are also effective. ${ }^{5}$

The presence of a clown seems to have a positive effect on preoperative anxiety, ${ }^{6-8}$ but no effect when the anesthesia mask is introduced. ${ }^{7}$ The same is true for music therapy. ${ }^{9}$ The use of clowns is not always easy because of resistance from medical staff. ${ }^{8}$ Only a few studies on the effect of clowns have been carried out, and very little is known about the mode of action. ${ }^{10-12}$

Clinical practices involving botulinum toxin injections are multiple. ${ }^{13}$ Nitrous oxide seems to be more effective than enteral midazolam and with less sedation. ${ }^{14}$ Nitrous oxide and anesthetic cream only seem to be effective for about $50 \%$ of children treated
Correspondence: Lars Kjaersgaard

Hansen

Department of Paediatrics,

Hans Christian Andersen Children's

Hospital, Odense University Hospital,

Odense, Denmark

Tel +45 $6480 \quad$ I 664

Fax $+45659 \mid 1862$

Email lars.kjaersgaard@dadlnet.dk 
with botulinum toxin, which is much lower than for other types of acute induced pain. ${ }^{15}$ Botulinum toxin injections in children with cerebral palsy and varying levels of cognitive development may indicate the need for specific improvements in the analgesic approach. ${ }^{15}$

We considered it important to evaluate the benefit of the presence of a clown at pediatric procedures because scant research exists on this topic, and because clowns are often part of daily practice in children's hospitals. We tested the effect of the presence of a clown on the duration of crying in children receiving botulinum toxin injections.

\section{Methods and patients}

This study was of prospective, cluster randomized design, in which the effect of presence of a clown was compared with that of usual care. Consecutively and prospectively, we enrolled 121 botulinum toxin treatments carried out in 60 children, who were randomly exposed to the clown's presence. The age range of the children was 0-15 years. Children with impaired sensibility were excluded, eg, those with a bifid spine. This outpatient study took place during a 2-year period ending in May 2009. Every third week, 5-6 treatments were carried out. When the clown was present, she took part in all treatments on that day. The same clown was used throughout the study. The treatments were administered alternately by MK (female, 52 years) and LKH (male, 49 years), both of whom were neuropediatricians. In the treatment room, the child was accompanied by the mother (sometimes both parents), and also present were the doctor, nurse, physiotherapist, and, randomly for the specific day, a clown (female, 44 years). Injections were specified at earlier consultations, as per digitalized gait analysis. The clown joined the child in the waiting room 15 minutes before the treatment. She participated in the treatment room and joined the child and the family a few minutes after leaving the treatment room. The child and parents did not know that the clown was going to be present. Prior to this study, the clown had not been part of usual care. The clown came from a hospital in another part of the country. The clown distracted the child, trying to be inferior to the child and making an alliance with the child, thereby allowing the child a superior role to increase its self-esteem. The clown mirrored and amplified the child's reactions, enabled and accepted the child's expressions, and was verbal if appropriate. The clown decided herself on the appropriate way of interacting with the child, according to the child's emotional state. She dressed the same way, with a big skirt, a painted face, and a big red nose at every session.
Crying duration after the first injection was the primary outcome measure, and was recorded using a stop watch. Breaks shorter than 120 seconds were included in crying duration. When crying ended, the time elapsed was written down, but the watch was not stopped. If the child started crying again within the next 120 seconds, the time until the cessation of the next bout of crying was recorded. The children were recommended to have buccal midazolam 15 minutes before injection. No topical anesthetic was used.

In order to obtain a statistical power of $80 \%$ in the study we needed to enroll $2 \times 50$ subjects to detect a true difference of 45 seconds in crying time in the presence and absence of a clown. The data were analyzed using a linear mixed effect model with random effect of the child due to the fact that we had more than one observation for some of the children. Included in the model were age, gender, treatment ( \pm clown), crying ahead of session (yes/no), number of injections, number of previous treatments, type of cerebral palsy, amount of botulinum toxin, dose of midazolam, and treating doctor (MK or LKH). We allowed for an interaction between treatment and gender. The response, ie, duration of crying, was power-transformed using a power of 0.6 to meet the requirements of the model, and then a stepwise procedure was used, removing nonsignificant terms. A linear effect of quantitative explanatory variables was checked using partial residual spots, and none of these were transformed.

\section{Results}

Twenty-six girls underwent 48 treatments and 34 boys underwent 73 treatments. The children were aged 14 months to 15 years, with a mean age of 4 years. Two children had five treatments, one child had four treatments, 15 children had three treatments, 17 children had two treatments, and 25 children had one treatment session during the study period. Thirty-two children were treated for the first time. No age difference between the genders was observed. Four children were excluded, three because they did not want the clown to be present, and one child because he wanted the clown to be present. Nearly all the children had a diagnosis of cerebral palsy. Six treatments were performed for diagnoses other than cerebral palsy, ie, muscular imbalance of DuchenneErbs paresis, excessive salivation, and muscle contracture in rheumatic disease. Most of the children (86\%) had sedation with midazolam, and $80 \%$ received it buccally. The median dose was $0.4(0.1-0.5) \mathrm{mg} / \mathrm{kg}$. One to ten muscles (median four) received 1-12 injections (median four). Most often, only the lower extremities were treated ( $82 \%) ; 12 \%$ of the sessions included both upper and lower limbs, and in 5\% 
only the upper limbs were treated. The botulinum toxin was used at a dose of 100 units $/ \mathrm{mL}$. The children were injected with 20-360 (median 170) units. Most children (74\%) did not cry before the injections. After the first injection, one quarter (26\%) did not cry. The rest cried for 5-660 (median 122) seconds. The clown was present at 28 sessions with LKH and 25 with MK. The number of sessions without the clown (see Table 1) was 29 (LKH) and 39 (MK).

The clown's presence was checked for different effects at different ages, and no relationship with age was found $(P=0.25)$. For the entire group, the effect of the clown's presence was markedly influenced by gender $(P=0.016)$, with a significantly positive effect for girls $(P=0.05)$, and a nonsignificant negative effect for boys $(P=0.14)$. We found the following correlations, all other parameters being equal: increased crying with increasing number of injections $(P<0.001)$, if the child had had previous treatments $(P=0.023)$, and crying before injections $(P<0.001)$; less crying with increasing age $(P=0.001)$ and quadriplegic type of cerebral palsy $(P=0.004)$; no change in crying with change in the amount of botulinum toxin (0.89), dose of midazolam $(P=0.36)$, or treating doctor $(P=0.59)$.

The 32 children (16 girls and 16 boys) treated for the first time showed no significant effect of the presence of the clown, and no difference between the genders was seen. Analysis of 99 treatments in children aged younger than 8 years showed that the results were the same, in other respects with a significant clown/gender interaction $(P=0.002)$ and a positive effect for girls $(P=0.04)$, but a negative effect for boys $(P=0.01)$.

\section{Discussion}

The effect of the presence of a clown during medical procedures in children has been studied rarely. Our results show heterogeneity in responses. For all 121 treatments, we found a difference in response between the genders and a positive effect for girls. For the 99 treatments in children younger than 8 years of age, the same was found, but with a clear negative effect for boys. A group of 32 children being treated for the first time showed no difference between the genders and no significant effect of the presence of the clown. Different anxiety scales and behavioral questionnaires are available

Table I The I2I treatments compared according to gender and presence of clown, with mean crying duration in seconds

\begin{tabular}{lll}
\hline & Clown & No clown \\
\hline Girls & $23(62)$ & $25(132)$ \\
Boys & $30(160)$ & $43(86)$ \\
\hline
\end{tabular}

for assessment, each offering advantages, but ratings are difficult to make. We chose crying duration, which is easiest to measure. We assumed duration of crying could be useful for assessing the degree of suffering of a child with cerebral palsy, although we are well aware that by simplifying the many aspects of the effect of the clown's presence to only this measure, we may have missed other valuable information. Furthermore, it is possible that some distressed children did not cry. Limitations of our study include the nonblinded recording of crying duration, and the fact that children who had been treated previously were confounded by experience with the clown and earlier treatments.

This study raises the question of why the female clown had a positive effect only on girls at repeated treatment sessions and a negative effect on the younger boys at repeated sessions. There seems to be few plausible explanations for these findings, which were also unexpected to the skilled female clown. Perhaps the female child makes an alliance more easily and identification with the female clown had a positive effect, especially at subsequent treatment sessions. There is limited information available about any possibly higher general anxiety level in male children prior to anesthesia. ${ }^{3}$ A negative experience at an earlier botulinum toxin injection session could explain any increase in crying duration. The many people in the neuropediatric treatment room could increase the child's anxiety and also dilute the influence of the clown. Future studies should take into account the effect of the clown's gender and the confounding effect of repeated treatment sessions.

\section{Acknowledgment}

The clown's salary was funded outside the hospital budget, ie, from several private donations for the care of sick children.

\section{Disclosure}

The authors report no conflicts of interest in this work.

\section{References}

1. Yip P, Middleton P, Cyna AM, Carlyle AV. Non-pharmacological interventions for assisting the induction of anaesthesia in children. Cochrane Database Syst Rev. 2009;3:CD006447.

2. Chundamala J, Wright JG, Kemp SM. An evidence based review of parental presence during anesthesia induction and parental/child anxiety. Can J Anaesth. 2009;56:57-70.

3. Patel A, Schieble T, Davidson M, et al. Distraction with a hand-held video game reduces pediatric preoperative anxiety. Paediatr Anaesth. 2006;16:1019-1027.

4. Uman LS, Chambers CT, McGrath PJ, Kisely S. Psychological interventions for needle-related procedural pain and distress in children and adolescents. Cochrane Database Syst Rev. 2006;4:CD005179. 
5. Chambers CT, Taddio A, Uman LS, McMurtry CM; HELPinKIDS Team. Psychological interventions for reducing pain and distress during routine childhood immunizations: A systematic review. Clin Ther. 2009;31:77-103.

6. Canto MA, Quiles JM, Vallejo OG, et al. Evaluation of the effect of hospital clowns performance about anxiety in children subjected to surgical intervention. Cir Pediatr. 2008;21:195-198. [Spanish].

7. Golan G, Tighe P, Dobija N, Perel A, Keidan I. Clowns for the prevention of preoperative anxiety in children: A randomized controlled trial. Paediatr Anaesth. 2009;3:262-266.

8. Vagnoli L, Caprilli S, Robiglio A, Messeri A. Clown doctors as a treatment for preoperative anxiety in children: A randomized, prospective study. Pediatrics. 2005;116:e563-e567.

9. Kain ZN, Caldwell-Andrews AA, Krivutza DM, et al. Interactive music therapy as a treatment for preoperative anxiety in children: A randomized controlled trial. Anesth Analg. 2004;98:1260-1266.
10. Adams P. Humour and love: The origination of clown therapy. Postgrad Med J. 2002;78:447-478.

11. Spitzer P. The clown doctors. Aust Fam Physician. 2001;30:12-16.

12. Kringelbach ML, Berridge KC. Towards a functional neuroanatomy of pleasure and happiness. Trends Cogn Sci. 2009;13:479-487.

13. Bakheit AM. Botulinum toxin in the management of childhood muscle spasticity: Comparison of clinical practice of 17 treatment centres. Eur J Neurol. 2003;10:415-419.

14. Zier JL, Rivard PF, Krach LE, Wendorf HR. Effectiveness of sedation using nitrous oxide compared with enteral midazolam for botulinum toxin A injections in children. Dev Med Child Neurol. 2008;50: 854-858.

15. Brochard S, Blajan V, Lempereur M, et al. Effectiveness of nitrous oxide and analgesic cream (lidocaine and prilocaine) for prevention of pain during intramuscular botulinum toxin injections in children. Ann Phys Rehabil Med. 2009;52:704-716.
Journal of Pain Research

\section{Publish your work in this journal}

The Journal of Pain Research is an international, peer-reviewed, open access, online journal that welcomes laboratory and clinical findings in the fields of pain research and the prevention and management of pain. Original research, reviews, symposium reports, hypothesis formation and commentaries are all considered for publication.

\section{Dovepress}

The manuscript management system is completely online and includes a very quick and fair peer-review system, which is all easy to use. Visit http://www.dovepress.com/testimonials.php to read real quotes from published authors. 